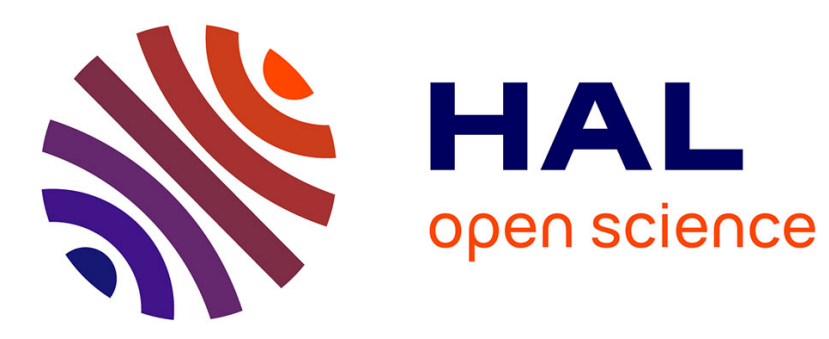

\title{
n-type phosphorus-doped polycrystalline diamond on silicon substrates
}

\author{
Slimane Ghodbane, Franck Omnès, Etienne Bustarret, Céline Tavares, \\ François Jomard
}

\section{- To cite this version:}

Slimane Ghodbane, Franck Omnès, Etienne Bustarret, Céline Tavares, François Jomard. n-type phosphorus-doped polycrystalline diamond on silicon substrates. Diamond and Related Materials, 2008, 17, pp.1324. 10.1016/j.diamond.2008.01.090 . hal-00761492

\section{HAL Id: hal-00761492 \\ https://hal.science/hal-00761492}

Submitted on 5 Dec 2012

HAL is a multi-disciplinary open access archive for the deposit and dissemination of scientific research documents, whether they are published or not. The documents may come from teaching and research institutions in France or abroad, or from public or private research centers.
L'archive ouverte pluridisciplinaire HAL, est destinée au dépôt et à la diffusion de documents scientifiques de niveau recherche, publiés ou non, émanant des établissements d'enseignement et de recherche français ou étrangers, des laboratoires publics ou privés. 


\title{
n-type phosphorus-doped polycrystalline diamond on silicon substrates
}

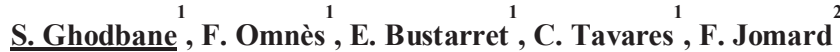 \\ 1 Institut Néel-CNRS, Dpt. nanosciences 25, Av des Martyrs 38042 Grenoble Cedex 09 FRANCE, \\ 2 GEMaC-UMR 8635 CNRS, 1 place A. Briand, 92195 Meudon Cedex FRANCE.
}

slimane.ghodbane@grenoble.cnrs.fr

\begin{abstract}
The microwave plasma-assisted deposition of reproducible and homogeneously n-type phosphorusdoped polycrystalline (microcrystalline) diamond films on silicon substrates is described. The phosphorus incorporation is obtained by adding gaseous phosphine $\left(\mathrm{PH}_{3}\right)$ to the gas mixture during growth. The low $\mathrm{CH}_{4} / \mathrm{H}_{2}$ ratio $(0.15 \%)$ and the use of the same growth parameters as for homoepitaxial $\{111\}$ films, led to a good crystalline quality of the continuous polycrystalline diamond layers, confirmed by SEM images and Raman spectroscopy measurements.

Secondary-ion mass spectrometry (SIMS) analysis measured a phosphorus concentration $[\mathrm{P}]$ of at least $7 \times 10^{17} \mathrm{~cm}^{-3}$. Cathodoluminescence spectroscopy in our P-doped polycrystalline films shows a phosphorus bound exciton $\left(\mathrm{BE}^{\mathrm{TO}}{ }_{\mathrm{P}}\right)$ peak between 5.142 and $5.181 \mathrm{eV}$. Cathodoluminescence and Ramaneffect spectroscopy confirmed the improvement of the crystalline quality of our films as well as a decrease in the intensity of the internal strain when the grain size was decreased. Cathodoluminescence imaging and SIMS depth profile of phosphorus demonstrated a very good homogeneity of phosphorus incorporation in the films.
\end{abstract}

Keywords: n-type doping, MPCVD polycrystalline diamond, phosphorus incorporation.

\section{Introduction}

Though p-type doping of diamond has been well established for quite a long time [1], and is considered relatively easy to obtain, mainly by adding a source of boron atoms to the gas mixture during growth, n-type doping of diamond films however remains an issue. Up to now, very few laboratories around the world have demonstrated their ability to achieve n-type doped homoepitaxial diamond films [2-4]. Different elements have been used for the n-type doping of diamond, including sulphur [5] and nitrogen [6]. Unfortunately, the efficiency of doping by such elements was limited. A new way to obtain $\mathrm{n}$-type doping in diamond films is the creation of boron-deuterium $\left(\mathrm{B}-\mathrm{D}_{2}\right)$ complexes by diffusing deuterium atoms into the diamond layer. Though promising results have been published [7], this process is not well understood and the stability of the $\mathrm{B}-\mathrm{D}_{2}$ at high temperatures is a serious limitation.

The first reproducible and relatively efficient n-type doping of $\{111\}$-homoepitaxial diamond films has been successfully achieved by S. Koizumi et al [2] in 1997. Yet today, phosphorus is still the most effective and known n-type dopant of diamond. Recently, the success of H. Kato et al. [8] in achieving the first n-type phosphorus-doped $\{100\}$-homoepitaxial diamond films demonstrated the possibility of ntype doping within this crystallographic orientation.

In contrast, only a few attempts of doping polycrystalline films by phosphorus incorporation have been undertaken $[9,10]$. This is possibly because of the well known sensitivity of phosphorus incorporation to the crystalline quality [11], usually lower in polycrystalline than in homoepitaxial films.

To our knowledge, H. Sternschulte et al. [9] have been the first to prove by cathodoluminescence measurements the possibility of n-type doping in polycrystalline diamond films using phosphorus incorporation. M. Nesladek et al. [10] have achieved phosphorus doped polycrystalline diamond films using a specific homoepitaxial growth strategy. After growing a thick undoped polycrystalline diamond layer 
onto the silicon substrate, the top of the diamond layer was polished, and then a second layer of phosphorus doped diamond was deposited on the polished surface of the first. The morphology of their polycrystalline films is similar to that of homoepitaxial films (large grain size, the phosphorus doped layer is not deposited directly on the silicon substrate).

In this work, we present the first n-type phosphorus-doped polycrystalline diamond films deposited directly on silicon substrates. The concentration of phosphorus is measured by secondary-ion mass spectrometry (SIMS). The influence of the grain size on the residual strain in the films as well as on their crystalline quality was also discussed using low-temperature cathodoluminescence and UV-excited Raman spectroscopy measurements.

\section{Experimental details}

The polycrystalline diamond films presented in this work have been deposited directly on $\{111\}$ oriented silicon substrates, using the microwave plasma-assisted chemical vapour deposition technique in a NIRIM-type reactor. In order to enhance the diamond nucleation density, the silicon substrates have been mechanically scratched by an industrial paste containing $9 \mu \mathrm{m}$-sized diamond powder. $\mathrm{Low}_{\mathrm{CH}} / \mathrm{H}_{2}$ ratio $(0.15 \%)$ was used in order to obtain the necessary high crystalline quality to which the incorporation of phosphorus in diamond films is very sensitive $[2,8]$. The subsequent growth rate was typically $0.1-0.2 \mu \mathrm{m} / \mathrm{h}$. The phosphorus/carbon $(\mathrm{P} / \mathrm{C})_{\text {gas }}$ ratio was $1000 \mathrm{ppm}$ in the gas phase for all samples. The temperature and the total pressure of the gases during growth were $880^{\circ} \mathrm{C}$ and 30 Torr respectively.

Cathodoluminescence measurements have been performed at liquid helium temperature $(5 \mathrm{~K})$ and high vacuum (4 $\times 10^{-6}$ Torr), using a Quanta 200 SEM equipped with a low temperature stage and a collecting mirror coupled to a CCD array through a high-resolution R 460 Jobin \& Yvon spectrometer using electron beam voltages between 0.2 and $30 \mathrm{kV}$. The spectra have been recorded each one during $150 \mathrm{~s}$, between 4.9 and $5.4 \mathrm{eV}$ (exciton energy range). The experimental points are recorded each $0.9 \mathrm{~nm}$, therefore with an energy resolution of $2 \mathrm{meV}$.

Raman spectra were recorded under ambient air at room temperature using a Jobin \& Yvon LabRam infinity micro-Raman spectrometer equipped with a liquid-nitrogen-cooled CCD detector, under excitation at $325 \mathrm{~nm}$ from a He-Cd laser source. Using a grating of $2400 \mathrm{gr} . \mathrm{mm}^{-1}$, the resolution of the spectrometer was less than $2 \mathrm{~cm}^{-1}$.

High resolution SIMS analysis using Cameca IMS $4 \mathrm{f}$ equipment have been performed to measure the phosphorus concentration as well as the depth distribution of other impurities ( $\mathrm{Si}, \mathrm{O}$ ). $\mathrm{Cs}^{+}$was chosen as primary ion source and accelerated to $10 \mathrm{keV}$. Phosphorus concentration has been quantified using $\{111\}$-homoepitaxial standard samples. The absolute accuracy is estimated to be around $\pm 10 \%$.

\section{Results and discussion}

Fig. 1 displays the scanning electron microscopy images from the 3 phosphorus doped polycrystalline films investigated in this paper and exhibiting different grain sizes, together with their respective cathodoluminescence spectra in the exciton energy range. The main shape of the grains' facets is triangular, indicating a main crystallographic orientation of the grains within $\{111\}$ axis. We know from homoepitaxial diamond films, that the incorporation of phosphorus is more efficient within $\{111\}$-oriented surfaces than within $\{100\}$. This is favorable in our case, as our aim is to achieve the maximum incorporation of phosphorus atoms in our films. Nevertheless, these films are not highly oriented (no bias applied during growth), we notice in particular in the PN04 layer the existence of more square shaped facets indicating $\{100\}$-oriented grains.

The growth time of the PN10 layer was 48 hours, which led to a grain size of $6 \mu \mathrm{m}$ (Fig. 1). Cathodoluminescence spectrum from this film clearly exhibits the peak corresponding to the bound exciton related to phosphorus $\left(\mathrm{BE}^{\mathrm{TO}}{ }_{\mathrm{P}}\right)$ at $5.142 \mathrm{eV}$. This proves that the incorporation of phosphorus in our polycrystalline films has effectively occurred $[8,9,12,13]$. Moreover, the presence of this peak means that the phosphorus is at the doping site (substitutional site) from the diamond lattice, and therefore demonstrates the n-type doping in our polycrystalline diamond films. 
The position of the $\mathrm{BE}^{\mathrm{TO}}{ }_{\mathrm{P}}$ peak is given at $5.18 \mathrm{eV}$ in the literature for phosphorus doped $\{111\}$ homoepitaxial diamond films $[12,13]$. In our phosphorous-doped polycrystalline films, the $\mathrm{BE}^{\mathrm{TO}}{ }_{\mathrm{p}}$ peak shifts to lower energies as the film thickness, the grain size and the internal strain increase together. In the PN10 layer (average grain size of $6 \mu \mathrm{m}$ ), the position of the $\mathrm{BE}^{\mathrm{TO}}{ }_{\mathrm{P}}$ peak is downward shifted to 5.142 $\mathrm{eV}$. For a growth duration of only 20 hours in the PN11 film, the average grain size is $3 \mu \mathrm{m}$, leading to a position of the $\left(\mathrm{BE}^{\mathrm{TO}} \mathrm{p}\right)$ peak at $5.160 \mathrm{eV}$. This position is closer to that of the $\left(\mathrm{BE}^{\mathrm{TO}}{ }_{\mathrm{P}}\right)$ in the homoepitaxial phosphorus doped films $(5.180 \mathrm{eV})$ than that observed in the thicker PN10 sample. In the PN04 film (10 hours deposition leading to $1 \mu \mathrm{m}$-sized grains) the position of the $\mathrm{BE}^{\mathrm{TO}}{ }_{\mathrm{P}}$ peak is at exactly 5.181 $\mathrm{eV}$, which is the usual position of this peak in homoepitaxial phosphorus doped diamond films $[2,8,14$, 15]. While the presence of internal strain will be confirmed by the Raman measurements presented later in this work, the downward shift of the $\mathrm{BE}^{\mathrm{TO}}{ }_{\mathrm{P}}$ could not be attributed to any specific effect as in this study the grain size, thickness, internal strain and possibly doping level were not independent from each other.

The full-width at half maximum (FWHM) of the $\mathrm{BE}^{\mathrm{TO}}$ p peak can be related to the crystalline quality of the film [16]. The higher the crystalline quality, the lower is the FWHM of its $\mathrm{BE}^{\mathrm{TO}}{ }_{\mathrm{p}}$ peak. The value of this parameter decreases in our films as the grain size decreases, which means that the crystalline quality is improved for lower grain sizes. Among the films presented in this paper, the PN04 layer exhibits the best crystalline quality as the FWHM of its $\mathrm{BE}^{\mathrm{TO}}{ }_{\mathrm{P}}$ peak is only $18 \mathrm{meV}$. This is supported by the presence of the free exciton on its cathodoluminescence spectrum, while it is absent from the spectra of the thicker films.

Fig. 2 displays the detail of the exciton energy range from the PN04 film cathodoluminescence spectrum. Referring to the results of $\{111\}$ films, the peaks at $5.322 \mathrm{eV}, 5.241 \mathrm{eV}$, and $5.025 \mathrm{eV}$ are due to $\mathrm{P}$-donor bound-exciton emission associated with non-phonon NP, transverse acoustic TA, and TO $+\mathrm{O}$ phonons respectively. The presence of these peaks and in particular of the non-phonon emission, confirms that the phosphorus is located at the substitutional sites of the diamond lattice as donor atoms and that the crystalline quality is relatively good [16]. We know from homoepitaxial diamond films that the incorporation of phosphorus is more efficient within $\{111\}$ than within $\{100\}$ crystallographic axis [8]. In our polycrystalline films, we have compared the cathodoluminescence spectra of $\{100\}$ and $\{111\}$ facets from the same grain in the PN04 film. Fig. 3 shows the result of this comparison after the two spectra have been normalized on the Free-exciton peak $\left(\mathrm{FE}^{\mathrm{TO}}\right)$. It is clear that the intensity of the bound exciton related to phosphorus $\left(\mathrm{BE}^{\mathrm{TO}}{ }_{\mathrm{P}}\right)$ is higher within the $\{111\}$ than within the $\{100\}$ axis. The ratio between the intensities of the bound and the free exciton peaks $\left(\mathrm{I}_{\mathrm{BE}} / \mathrm{I}_{\mathrm{FE}}\right)$ is directly related to the phosphorus incorporation [17]. Moreover, the beam size in the conditions of our cathodoluminescence measurements is smaller than the size of each facet. Therefore we can conclude that the phosphorus concentration $[\mathrm{P}]$ is higher (by about $30 \%$ ) within $\{111\}$ than within $\{100\}$ axis.

Fig. 4a shows the Raman spectra of the films studied in this work, normalized to the diamond Raman first order peak, usually situated at $1332 \mathrm{~cm}^{-1}$ in natural diamond crystals [18] as well as in homoepitaxial [19] and polycrystalline [20] CVD diamond films. The G-band at $1572 \mathrm{~cm}^{-1}$ is the signature of the $\mathrm{sp}^{2} \mathrm{C}\left(\mathrm{C}=\mathrm{C}\right.$ bounds) [21]. In polycrystalline diamond films, the $\mathrm{sp}^{2} \mathrm{C}$ is located mainly in the grain boundaries [22]. The intensity of the G-band is very weak in the PN04 film because the grain boundaries are not completely formed. The carbon phase purity in this film is therefore relatively high. Comparing all films, the intensity of the $\mathrm{G}$ band and thus the $\mathrm{sp}^{2} \mathrm{C}$ concentration is higher when the thickness and grain size increase.

The structures forming the diamond Raman second order spectrum of the PN04 layer shown with a scale expansion in Fig. 4a are well defined. In a previous work we have shown that the diamond second order structures situated at $2177,2333,2467$, and $2667 \mathrm{~cm}^{-1}$ soften and broaden as the crystalline quality decreases [23].

Fig. 4b shows a scale expansion around the diamond Raman first order peaks from the films PN04, PN10 and PN11, brought to the same intensity. The position of this peak is exactly at $1332 \mathrm{~cm}^{-1}$ in PN04 film indicating no or very weak strain in it. The diamond first order peak position in PN10 and PN11 is upward shifted to $1336 \mathrm{~cm}^{-1}$. Keeping in mind that the resolution of the Raman spectra is less than $2 \mathrm{~cm}^{-}$ ${ }^{1}$, this upward shift indicates a strong compressive strain in these two films [24]. The upward shift of the diamond first order peak to $1336 \mathrm{~cm}^{-1}$ in PN10 and PN11 films is attributed to the residual strain generated during their growth. The mechanism responsible for the generation of this strain is explained as 
following: At the first stages of the growth, the diamond nuclei appear separately on the silicon substrate and are only weakly strained. A further growth leads to an increase of the three-dimensional expansion of the grains until they reach each other forming a continuous diamond layer (coalescence). If the growth continues beyond the coalescence step, the grains tend to push each other, generating thus the compressive strain which is responsible for the upward shift of the diamond Raman first order peak to higher wavenumbers. The SEM image of the PN04 film (Fig. 1) indicates that the coalescence step described above is just reached in this film, which means a very weak strain and therefore a position of its diamond first order peak at $1332 \mathrm{~cm}^{-1}$ (not shifted).

The FWHM of the diamond first order peak is about $6 \mathrm{~cm}^{-1}$ in the PN04 layer (grain size: $1 \mu \mathrm{m}$ ) indicating a relatively high crystalline quality of this film. The value of this parameter increases to $11 \mathrm{~cm}^{-1}$ for PN11 (grain size: $3 \mu \mathrm{m}$ ) and further to $14 \mathrm{~cm}^{-1}$ in PN10 (grain size: $6 \mu \mathrm{m}$ ). The FWHM of the diamond Raman first order peak is inversely proportional to the phonon lifetime, which is shortened by the defects present in the diamond lattice [25]. This means that the lower the FWHM, the higher is the crystalline quality of the films. Thus, the crystalline quality is improved when the grain size in our films decreases.

The phosphorus concentration in the PN04 film is measured by secondary-ion mass spectrometry (SIMS). The depth profile of phosphorus is plotted on Fig. 5. The phosphorus concentration is $7 \times 10^{17}$ $\mathrm{cm}^{-3}$. This value remains constant within the whole thickness of the film $(2.5 \mu \mathrm{m})$ and is comparable to the state-of-the-art maximum concentration of phosphorus in homoepitaxial diamond layers, which is $\sim 5$ $\times 10^{19} \mathrm{~cm}^{-3}$ in $\{111\}$ [26] and $10^{18} \mathrm{~cm}^{-3}$ in $\{100\}$ films [27]. From Fig. 1, the morphology of the grain facets' shapes in the PN04 film in which the [P] has been measured, exhibits a large part of $\{100\}$ oriented grain in which the incorporation of phosphorus is $30 \%$ lower than in the $\{111\}$ oriented grains, as demonstrated above in Fig. 3. The other films PN10 and PN11 are largely dominated by $\{111\}$ oriented grains. This logically means that their $[\mathrm{P}]$ is higher than $7 \times 10^{17} \mathrm{~cm}^{-3}$ and could reasonably reach $10^{18}$ $\mathrm{cm}^{-3}$. Other impurities $(\mathrm{O}$ and $\mathrm{Si}$ ) have also been detected during the SIMS measurements. Silicon atoms are more likely to rise from the substrate through the diamond layer. Contamination by silicon from the reaction chamber made from fused silica is not excluded.

We attribute the presence of oxygen atoms in our films to residual air in the reaction chamber or in the gases used in the growth. The concentration of oxygen atoms (not shown) significantly increases close to the film's surface. In a previous work, we reported a significant concentration of oxygenated chemical groups at the surface and subsurface of as grown homoepitaxial $[28,29]$ and polycrystalline diamond films [29]. Therefore this increase is attributed to a slight oxidation of the surface and subsurface by ambient air in which the samples were kept before the SIMS measurements have been performed.

After checking the distribution of phosphorus incorporation within the entire thickness of the PN04 layer, it is also necessary to check its repartition on the whole area of the film. To do so, we have performed cathodoluminescence images at the energy of the bound exciton related to phosphorus $\left(\mathrm{BE}^{\mathrm{TO}}{ }_{\mathrm{P}}\right)$. Fig. $6 \mathrm{~b}$ shows the results on a typical area of $21 \times 21 \mu \mathrm{m}^{2}$ from the PN04 film. The bright points are generated by emission from the $\mathrm{BE}^{\mathrm{TO}} \mathrm{p}$ and thus correspond to a doped area, while the dark points translate the absence of the $\mathrm{BE}^{\mathrm{TO}}{ }_{\mathrm{p}}$ and therefore a non-doped area. When comparing the cathodoluminescence image (Fig. 6b) to the SEM image (Fig. 6a) from the same area, it is clear that the bright points correspond exactly to the grains and the dark points to the grain boundaries and the uncovered areas of the silicon substrate. This means that the entire diamond layer is doped with phosphorus. The grain boundaries are mainly constituted by $\mathrm{sp}^{2} \mathrm{C}$ (non-diamond phases) and thus no phosphorus doping is expected in them. The homogeneity of the n-type doping with phosphorus in our polycrystalline diamond films is thus successfully revealed.

\section{Conclusion}

In this work, we have demonstrated the possibility of achieving reproducible and homogeneously ntype phosphorus-doped polycrystalline diamond films, deposited directly on silicon substrates (without buffer layer). During this study, we have presented 3 typical films, from a set of 12 deposited layers. All of them have been found by cathodoluminescence to be successfully doped with phosphorus. Raman spectroscopy measurements have revealed that when the grain size is decreased, the residual compressive 
strain intensity in the films decreases and their crystalline quality is improved. This improvement of the crystalline quality when the grain size decreases, has also been confirmed by cathodoluminescence measurements. The phosphorus concentration has been measured by secondary-ion mass spectrometry (SIMS) in one of the films (PN04) to be $7 \times 10^{17} \mathrm{~cm}^{-3}$. We have confirmed in this work, by cathodoluminescence measurements, that the incorporation of phosphorus is more efficient within $\{111\}$ than within $\{100\}$ crystallographic direction even in the same grain. This means the PN04 layer containing a large part of $\{100\}$ oriented grains, is likely not to be the most doped film. It is therefore reasonable to expect a higher concentration of phosphorus in the two other layers (PN10 and PN11) which contain mainly $\{111\}$ oriented grains. The SIMS depth profiles have also shown the presence of other impurities $(\mathrm{O}, \mathrm{Si})$ with weak concentrations.

Finally, both SIMS depth profile of phosphorus and cathodoluminescence images have respectively demonstrated the homogeneity of the phosphorus incorporation within the whole thickness and its uniform distribution on the entire area of the film.

\section{Acknowledgements}

The authors would like to thank the French ministry of industry for supporting this work. We sincerely thank Eng. François Jomard for SIMS measurements, Eng. Pierre Giroux from Institut Néel in CNRS of Grenoble for his help to the well progress of diamond growth, and the other members of the same group for valuable advice and rich discussions.

\section{References}

[1] A. Deneuville "Boron doping of diamond films from the gas phase" in book "Thin film diamond I". C. Nebel and J. Ristein Edts, Semiconductors and semimetals. Vol. 76 Elsevier San Diego 2003

[2] S. Koizumi, in: C.E. Nebel, J. Ristein (Eds.), Semiconductors and Semimetals 76-Thin Film Diamond I, Elsevier

[3] N. Casanova, A. Tajani, E. Gheeraert, E. Bustarret, J. A. Garrido, C. E. Nebel, M. Stutzman. Diam. and Relat. Mat. 7 (2002) 540 Academic Press, Amsterdam, 2003, pp. 239.

[4] T.Kociniewski, J. Barjon, M.-A. Pinault, F. Jomard, A. Lusson,D. Ballutaud, O. Gorochov, J.M. Laroche, E. Rzepka, J. Chevallier, C. Saguy, Phys. Stat. Sol. (a) Appl. Res. 203 (2004) 3136

[5] J. Sakaguchi, M. N. Gamo, Y. Kikuchi, E. Yasu, H. Haneda, T. Suzuki, and T. Ando. Phys. Rev. B. 60 (1999) 2139

[6] E. Worner, E. Pleuler, C. Wild, and P. Koidl. Diamond and Relat. Mat. 12 (2003) 744

[7] Z. Teukam, J. Chevalier, C. Saguy, R. Kalish, D. Ballutaud, M. Barbé, F. Jomard, A. T. Carli, C. Cytermann, J. E. Butler, M. Bernard, C. Baron, A. Deneuville, Nature Materials 2 (2003) 482

[8] H. Kato, S. Yamazaki, and H. Okushi. Phys. Stat. Solid. 202 (2005) 2122

[9] H. Sternschulte, T. Albrecht, K. Thonke, R. Sauer, M. Grießer., and M. Grasserbauer. Mat. Res. Soc. Symp. Proc. 423 (1996) 693

[10] M. Nesladek, K. Haenen, J. D’Haen, S. Koizumi, H. Kanda, Phys. Stat. Solid. (a) Appl. Res. 199/1 (2003) 77.

[11] S. Koizumi, H. Ozaki, M. Kamo, Y. Sato, H. Ozaki, and T. Inuzuka. Appl. Phys. Lett. 71 (1997) 1065

[12] K. Tanabe, K. Nakazawa, J. Susantyo, H. Kawarada, and S. Koizumi. Diam. and Relat. Mat. 10 (2001) 1652

[13] A. Tajani, E. Gheeraert, N. Casanova, E. Bustarret, J.A. Garrido, G.Rumen, C.E. Nebel, M.E. Newton, D. Evans, Phys. Status Solidi, (a) Appl. Res. 193/3 (2002) 541

[14] A. Tajani, E. Gheeraert, N. Casanova, E. Bustarret, J.A. Garrido, G.Rumen, C.E. Nebel, M.E. Newton, D. Evans, Phys. Status Solidi, (a) Appl. Res. 193/3 (2002) 541.

[15] K. Tanabe, K. Nakazawa, J. Susantyo, H. Kawarada, and S. Koizumi. Diam. and Relat. Mat. 10 (2001) 1652 
[16] R. Sauer, Thin-film diamond I, in: C.E. Nebel, J. Ristein (Eds.), Semic. and Semimetals, 76 (2004) 379

[17] J. Barjon, P. Desfonds, M.-A. Pinault, T. Kociniewski, F. Jomard, and J. Chevallier, J. Appl. Phys. 101 (2007) 1

[18] A.V. Palnichenko, A.M. Jonas, J.C. Charlier, A.S. Aronin, J.P. Issi, Nature 402 (1999) 162

[19] R. Linares, and P. Doering, Diamond and Related Materials 8 (1999) 909

[20] A.J.S. Fernandes, M.A. Neto, F.A. Almeida, R.F. Silva, F.M. Costa, Diam. \& Relat. Mat. 16 (2007) 757

[21] A.C. Ferrari and J. Robertson, Phys. Rev. B 64 (2001) 75414

[22] Y. von Kaenel, J. Stiegler, E. Blank, Diam. and Relat. Mat. 4 (1995) 972

[23] S. Ghodbane, A. Deneuville, Diam. \& Relat. Mat.15 (2006) 589

[24] I.B. Yanchuk, M.Y. Valakh, A.Y. Vul, V.G. Golubev, S.A. Grudinkin, N.A. Feoktistov, A. Richter, and B. Wolf, Diam. and Relat. Mat. 13 (2004) 266

[25] A.W. Ashcroft, N.D. Mermin, Solid State Physics, Saunders Company (1976)

[26] M. Nesladek, Semicond. Sci. Technol. 20 (2005) R19

[27] H. Kato, S. Yamasak, H. Okushi. Diam. and Relat. Mat. 16 (2007) 796

[28] S. Ghodbane, D. Ballutaud, A. Deneuville, and C. Baron, Phys. Stat. Sol. (a) 203 (2006) 3147

[29] S. Ghodbane, A. Deneuville, D. Ballutaud, F. Omnès, C. Baron, M. Bernard, C. Agnès, Submitted to J. Appl. Phys.

\section{Figure caption:}

Fig. 1. SEM images and cathodoluminescence spectra from the n-type phosphorus-doped polycrystalline diamond films PN04 (grain size : $1 \mu \mathrm{m}$ ), PN11 (grain size : $3 \mu \mathrm{m}$ ), and PN10 (grain size : $6 \mu \mathrm{m}$ )

Fig. 2. Details of the exciton-energy range from the cathodoluminescence spectrum of the PN04 layer (grain size : $1 \mu \mathrm{m}$ )

Fig. 3. Cathodoluminescence spectra from $\{111\}$ and $\{100\}$ facets of the same grain in the PN04 layer, normalised on the intensity of the $\mathrm{FE}^{\mathrm{TO}}$

Fig. 4. (a): Raman spectra of the samples PN04 (grain size : $1 \mu \mathrm{m}$ ), PN11 (grain size : $3 \mu \mathrm{m}$ ), and PN10 (grain size : $6 \mu \mathrm{m}$ ), normalised on the diamond first order peak, (b): Scale expansion around diamond first order peak positions

Fig. 5. SIMS depth profile of phosphorus atoms in the film PN04

Fig. 6. (a): SEM image of $25 \times 25 \mu \mathrm{m}^{2}$ area from the film PN04, (b): Cathodoluminescence image centred on the $\mathrm{BE}_{\mathrm{TO}}^{\mathrm{P}}$ energy $(5.181 \mathrm{eV})$ from the same area 

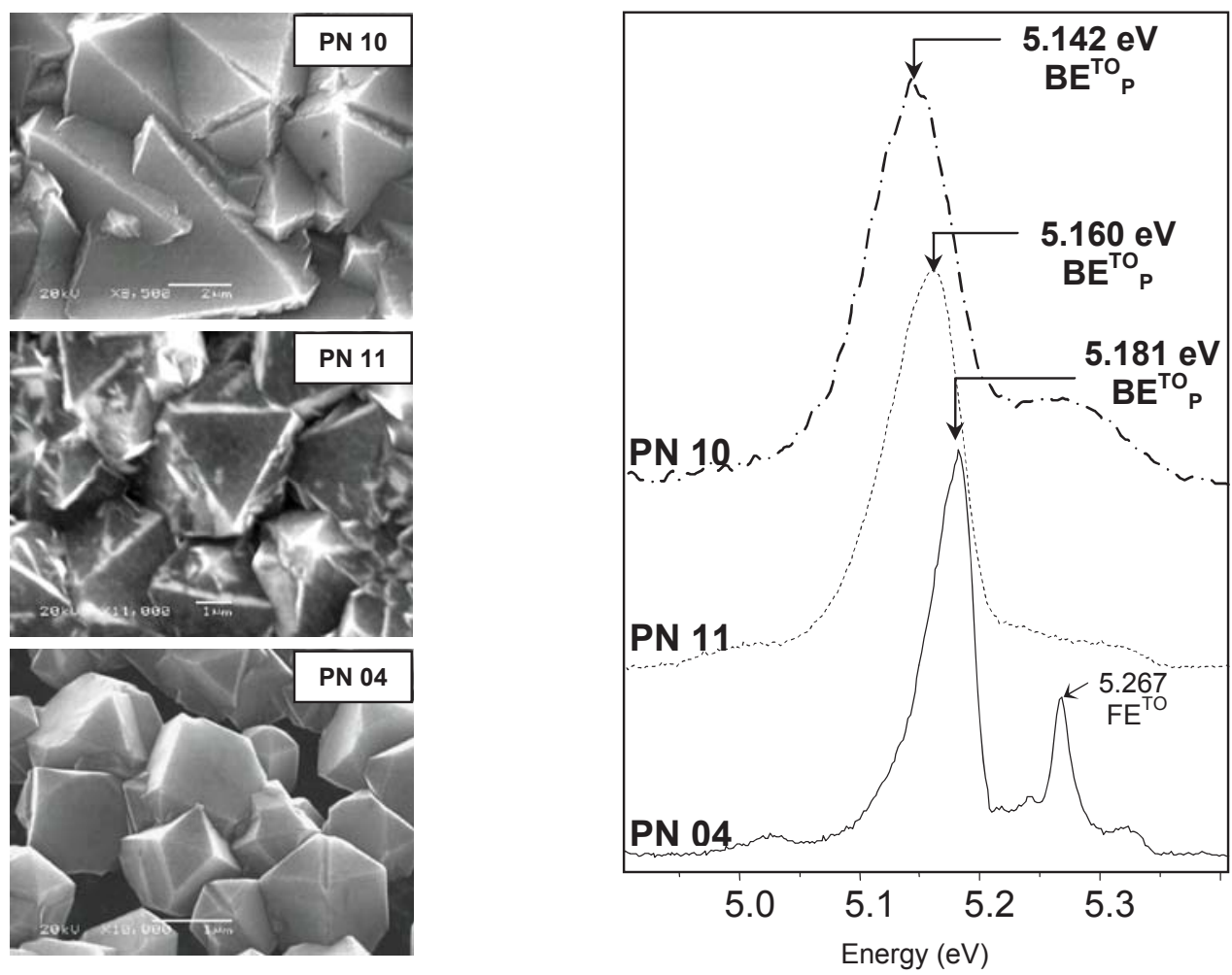

Fig. 1. SEM images and cathodoluminescence spectra from the n-type phosphorus-doped polycrystalline diamond films PN04 (grain size: $1 \mu \mathrm{m}$ ), PN11 (grain size: $3 \mu \mathrm{m}$ ), and PN10 (grain size: $6 \mu \mathrm{m})$ 


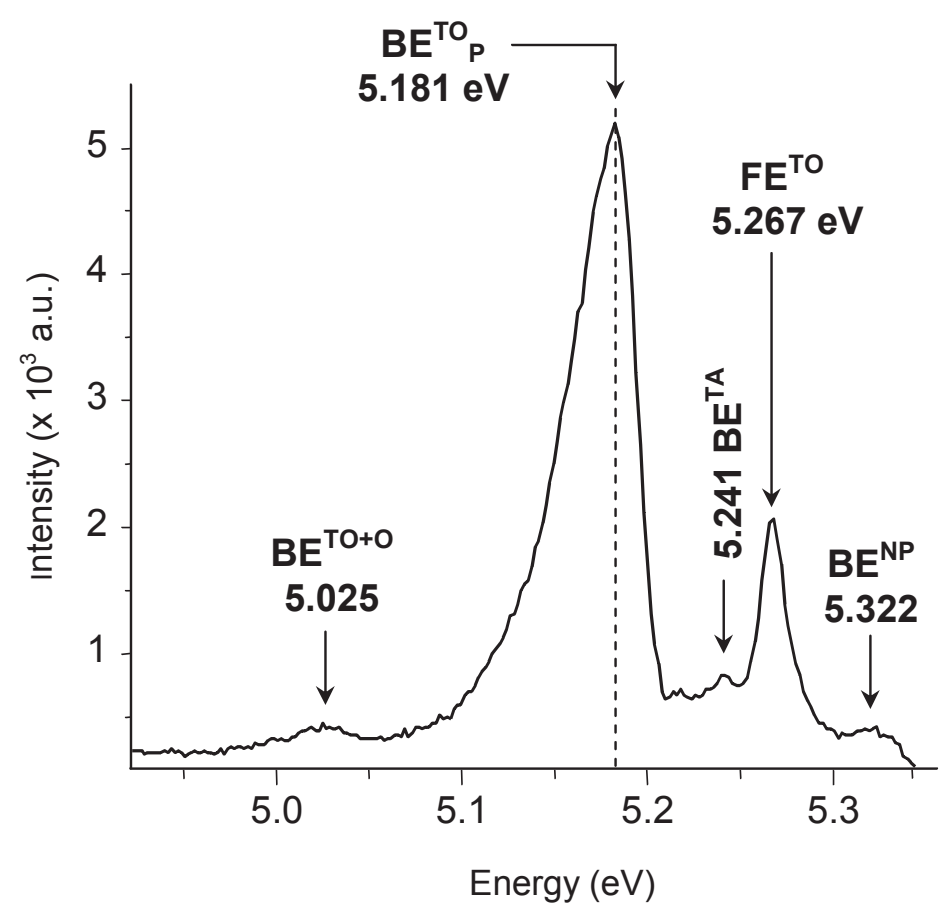

Fig. 2. Details of the exciton-energy range from the cathodoluminescence spectrum of the PN04 layer (grain size : $1 \mu \mathrm{m})$ 


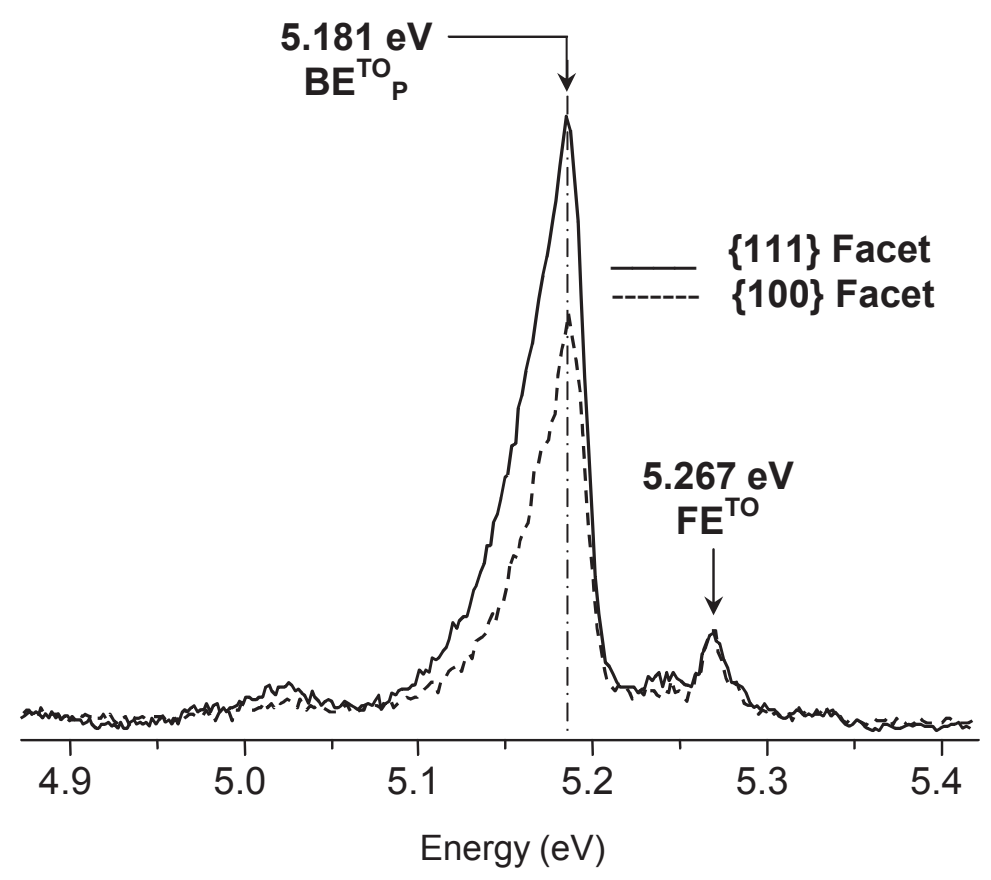

Fig. 3. Cathodoluminescence spectra from $\{111\}$ and $\{100\}$ facets of the same grain in the PN04 layer, normalised on the intensity of the $\mathrm{FE}^{\mathrm{TO}}$ 

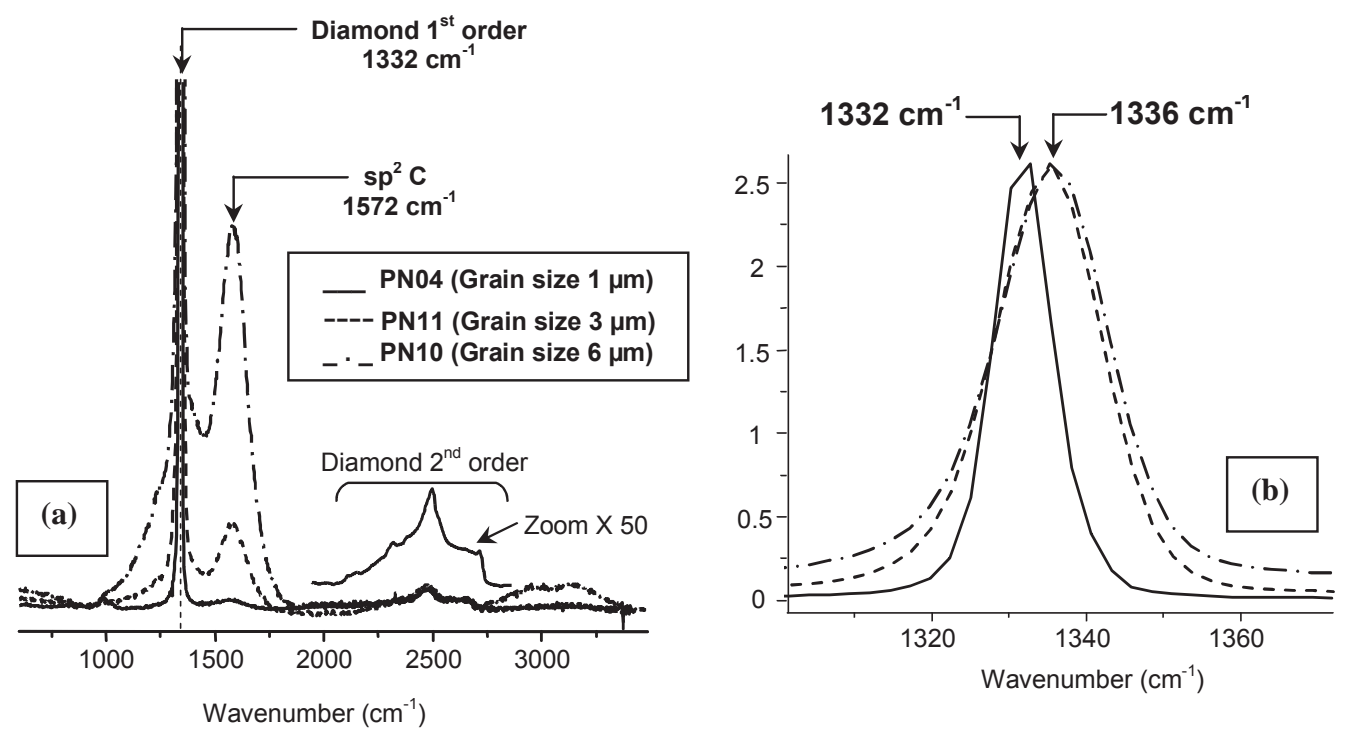

Fig. 4. (a): Raman spectra of the samples PN04 (grain size : $1 \mu \mathrm{m}$ ), PN11 (grain size : $3 \mu \mathrm{m}$ ), and PN10 (grain size : $6 \mu \mathrm{m}$ ), normalised on the diamond first order peak, (b): Scale expansion around diamond first order peak positions 


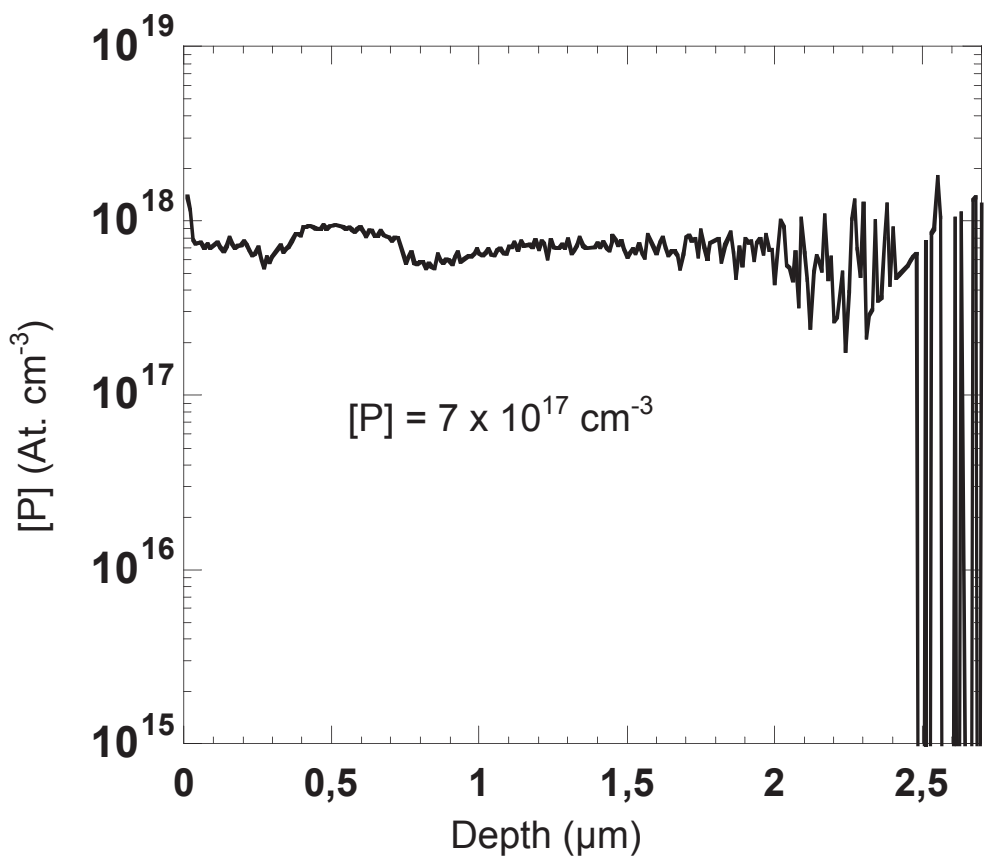

Fig. 5. SIMS depth profile of phosphorus atoms in the film PN04 

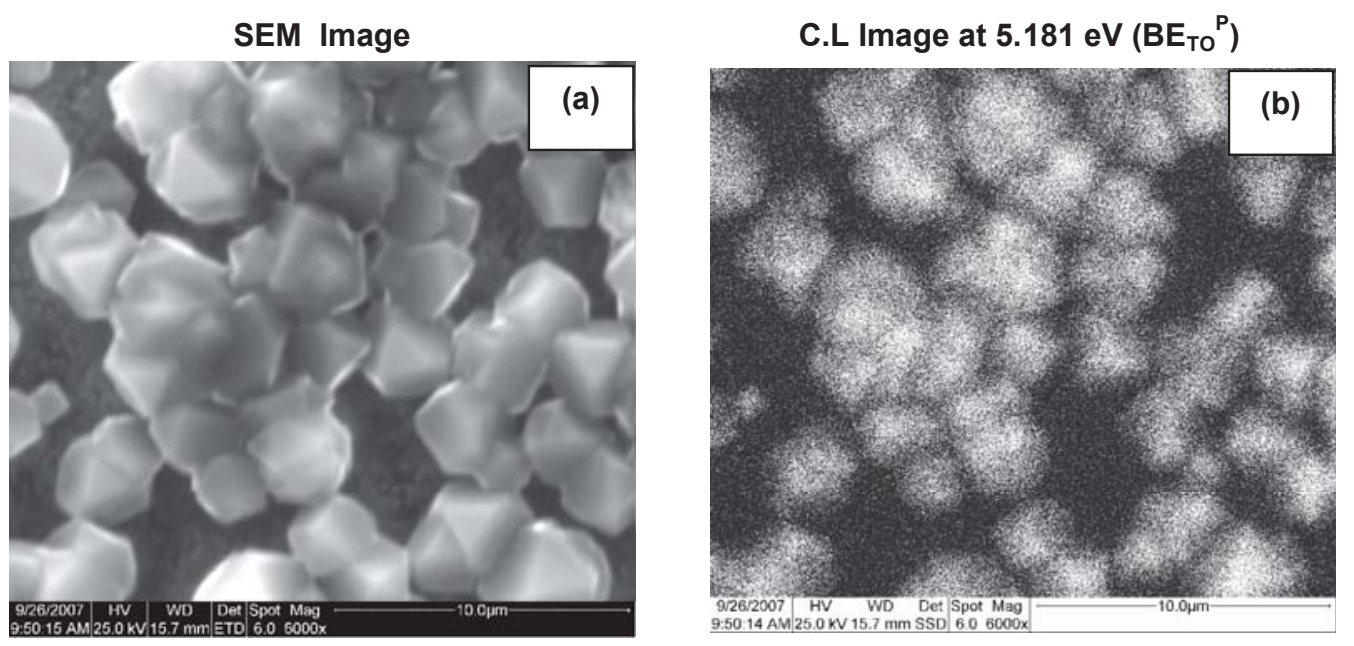

Fig. 6. (a): SEM image of $25 \times 25 \mu \mathrm{m}^{2}$ area from the film PN04,

(b): Cathodoluminescence image centred on the $\mathrm{BE}_{\mathrm{TO}}{ }^{\mathrm{P}}$ energy $(5.181 \mathrm{eV})$ from the same area.

Both images have been recorded in the same conditions $(5 \mathrm{~K}, 25 \mathrm{kV})$ 